\title{
Pathogenesis of nephrolithiasis
}

\author{
K Suranga N Wijayarathna, Anuruddha M Abeygunasekera
}

\author{
Colombo South Teaching Hospital, Kalubowila, Sri Lanka
}

\section{Key words: aetiopathogenesis; stone recurrence; stone prevention \\ Introduction}

Urinary stone disease is a common clinical problem as the lifetime risk of having a stone is $10 \%$ in the population [1]. Furthermore the incidence of nephrolithiasis is increasing with dramatic increases noted in females and children [2,3]. In addition there are changes in the frequency and composition of urinary calculi. For example the incidence of staghorn calculi is decreasing in the European countries and the proportion of struvite calculi among staghorn calculi is decreasing both in Europe and USA [4]. These trends are related to changes in lifestyle, dietary patterns and improving medical services [5]. Renal stones are commoner in men but the ratio varies in different parts of the world. In the West it is 2.7:1 while in Sri Lanka it is 3.6:1 [6,7]. Although staghorn calculi are commoner in women, in Sri Lanka there is a male preponderance with a ratio of $4: 1$ [8]. These differences suggest that patterns of stones differ in different geographical localities prompting scientists to believe in different aetio-pathogenesis as well. However the composition and distribution of renal stones in Sri Lanka do not differ in different parts of the country studied [9].

Fortunately profound advances in endoscopic design, durability and accessories have revolutionised the minimally invasive therapy of nephrolithiasis. Vast improvements in imaging techniques have been made during the recent past. These advances have made treatment of nephrolithiasis, patient friendly with minimal morbidity and short hospital stay. However treatment of nephrolithiasis does not end with successful removal of the offending stone. There is a high tendency for these stones to recur and within 5 years $35 \%$ to $50 \%$ of patients develop another stone [10]. Therefore prevention of a future recurrence of stones is an important necessity to avoid long term

Correspondence :Abeygunasekera AM

Email : amabey@sit.lk morbidity and improve the health of these people. In order to formulate preventive strategies it is imperative to understand the aetiopathology of nephrolithiasis.

\section{Pathogenesis}

There is no consensus on the aetiopathology of nephrolithiasis. This alone is sufficient indirect evidence for its multifactorial nature. However it is clear that pathogenesis of renal stones constitutes of two major steps. Firstly the immediate changes that occur at the site of stone formation. Secondly the general factors which induce and promote these changes at the site.

\section{Level I (at the tissue level)}

Supersaturation - Supersaturation occurs when the concentration of a stone-forming salt exceeds its solubility in a solution. This leads to formation of foci of its solid phase. Urine is a medium which is more complex than pure solution [11]. Therefore the required critical concentration for supersaturation may rise up to eightfold and new solids will not form during this period. This concentration range is called the metastable zone. Though new stones may not form in this range, existing stones may aggregrate and grow in the metastable zone. This has clinical importance as any tiny fragments of stones left after treatment may lead to bigger stone formation easily though new stone formation would be unlikely if the patient remains in the metastable zone. Exceeding supersaturation is the cause of uric acid and cystine calculi [12].

Plaque theory - In 1930s Randall described a precalculus lesion (plaque) in the renal papilla and proposed that a sub-epithelilal calcification of renal papilla becomes the nidus of calcium oxalate monohydrate papillary calculi, as a consequence of the disruption of the papillary epithelial layer by the hydroxyapatite (calcium phosphate) plaque [13]. Such plaques are present in all idiopathic calcium oxalate stone formers but not in healthy controls [14]. Recently, it was found that in patients susceptible to 
the development of calcium oxalate stones, the plaque is initiated in thin-loop of Henle basement membranes, basement membranes of collecting tubules, and the vasa recta [15]. However the initial trigger for this crystallization is not clear yet. A multifactorial process seems to be likely. An increased urinary calcium excretion and an acidic urinary $\mathrm{pH}$ have been incriminated as contributory factors that initiate the crystallization process by promoting apatite (calcium phosphate) depletion [16].

Recently there is another interesting hypothesis suggested as the mechanism for formation of plaques. Accordingly vasa recta play a major role in the process which is aptly termed the vascular theory [17]. The hypoxic and hyperosmolar environment in the papillary tip makes descending and ascending vasa recta vulnerable for changes which lead to atherosclerotic-like lesions and calcifications in its wall. These calcifications erode into papillary interstitium which enlarges supported by cellular promoters. Proponents of this vascular theory cite the higher incidence of stones in individuals with metabolic syndrome, diabetes mellitus and coronary artery disease as supporting evidence $[18,19]$.

Plaque formation is the most plausible theory so far to explain the formation of idiopathic calcium oxalate stones.

\section{Level II (general factors)}

Although these changes described above at the site of stone formation have been well described their importance to clinicians who manage patients with renal stones in real life is minimal. It is the general factors which induce and modify these pathological processes that are important for practicing clinicians. Interplay of three sets of general factors lead to formation of stones.

(i) Genetic/metabolic

(ii) Habits

(iii) Intrinsic factors related to the urinary tract

Genetic and metabolic factors that contribute to nephrolithiasis include hypercalciuria, hypercalcaemia, hyperoxaluria, hyperuriciosuria, hypocitraturia, hypomagnesaemia and renal tubular acidosis [20]. Some of these conditions when severe can cause stones on their own by exceeding supersaturation. But the majority leads to stone formation in the presence of other factors too. Genetic and metabolic factors can be divided into two broad categories. Diseases with generalised system involvement like hyperparathyroidism, sarcoidosis and gout constitute the first group. The second group include diseases with urinary tract manifestations only e.g. hypercalciuria, hyperoxaluria and hypocitraturia. Habits of individuals make a significant contribution to stone formation especially when the individuals have another predisposing factor categorised under genetic/ metabolic or urinary tract factors. An average adult should produce about 2 litres of urine a day [20]. To achieve this, a person living in a tropical country like Sri Lanka should drink about 3 litres of water a day. Those who work outdoors and engage in certain occupations are at risk of developing nephrolithiasis, e.g. labourers, drivers, masons and carpenters [8]. Such people should drink adequate amounts of water to avoid stone formation. Out of all possible measures of prevention this is the only intervention that has been proven consistently to be of value in prevention of nephrolithiasis [21]. It is cheap and realistic too when compared to other dietary interventions since these are life time changes. The quality of water in causation of stones is a contentious issue. Hard water when boiled is free of excess calcium salts and theoretically safe to be consumed [22]. Some have queried whether high fluoride content in water potentiates renal calculi formation $[1,23]$. Although it is possible theoretically there is no convincing evidence to prove it.

A monotonous diet has been incriminated with formation of renal stones [1]. Animal proteins, by providing a high acid load may promote stones. An acidic urinary $\mathrm{pH}$ leads to an increased bicarbonate resorption into the renal medulla and a consequent increase in interstitial $\mathrm{pH}$ that causes calcium phosphate depletion [16]. Though many advise restriction of calcium rich food, it may be useful only in a small number of patients with absorptive hypercalciuria [24]. On the other hand a low calcium diet is proven to cause renal stones and is harmful to bone and dental health [25]. Effect of calcium supplementation on known stone formers appears to be counter-productive [26]. If calcium supplements are essential due to other medical reasons, it will be a wise move to assess the 24 hour urinary calcium level from time to time before deciding to continue supplementation. If calcium supplements are to be taken they should be taken after meals to minimise hypercalciuria. Those with intestinal hyperoxaluria could avoid oxalate rich food like cocoa based products, spinach, asparagus, tomatoes, rhubarb and parsley. Restriction of red meat and nuts is useful in patients with raised uric acid levels in blood and urine.

In the absence of sophisticated laboratory facilities to identify individual metabolic derangements, a sensible 
approach to adjust the diet would be more practical and have a better compliance in preventing urolithiasis in susceptible individuals. A diet consisting of fruits, vegetables, low salt, low protein and a balanced intake of calcium, fats and carbohydrate should be the recommended diet for stone formers. Citrate supplementation with lemon or orange juice would be useful [27]. Citrate is one of the inhibitors of urolithiasis. The others are magnesium, pyrophosphate, protease inhibitors and glycosaminoglycan. Indigenous herbal products may help in expulsion of small stones or may prevent stone formation by contributing to the fluid intake if taken regularly [28,29].

The possible urinary tract factors that cause renal stone formation include infections with ureaseproducing organisms leading to alkaline urine, urinary stasis due to obstruction and foreign bodies lodged in the urinary tract. Alkaline urine is known to produce struvite stones. This was believed to be the main cause of staghorn calculi traditionally. However it has been shown now that most staghorn calculi are not struvite stones and are not associated with urease-producing organisms [30]. Stasis due to obstruction (e.g. congenital pelvi-ureteric junction obstruction) is well known as an underlying cause of nephrolithiasis though every patient with obstruction does not produce stones even when longstanding. Foreign bodies like forgotten ureteric stents and shrapnel lodged inside the kidney can be the focus of stone formation.

\section{Preventive measures}

Measures to prevent stone recurrence can be delivered at three levels (Panel 1).

The first constitutes general advice about dietary and drinking habits. Such advice is useful to all patients with stone disease. A diet consisting of fruits, vegetables, low salt, low protein and a balanced intake of calcium, fats and carbohydrate is recommended for
Panel 2 - Recommended pharmacological treatments for aggressive, recurrent stone formers

\begin{tabular}{|c|c|}
\hline Urine abnormality & Therapeutic agent \\
\hline $\begin{array}{l}\text { High excretion of } \\
\text { calcium }\end{array}$ & $\begin{array}{l}\text { Thiazide, } \\
\text { Orthophosphate }\end{array}$ \\
\hline $\begin{array}{l}\text { High excretion of } \\
\text { oxalate }\end{array}$ & $\begin{array}{l}\text { Dietary restriction of } \\
\text { oxalate, potassium citrate }\end{array}$ \\
\hline $\begin{array}{l}\text { Low excretion of } \\
\text { citrate }\end{array}$ & Potassium citrate \\
\hline $\begin{array}{l}\text { Low excretion of } \\
\text { magnesium }\end{array}$ & Thiazide+Mg \\
\hline $\begin{array}{l}\text { Renal tubular } \\
\text { acidosis }\end{array}$ & Potassium citrate \\
\hline Low urinary $\mathrm{pH}$ & Potassium citrate \\
\hline $\begin{array}{l}\text { High excretion } \\
\text { of urate }\end{array}$ & Allopurinol \\
\hline $\begin{array}{l}\text { Brushite } \\
\text { stone }\end{array}$ & Thiazide+Mg \\
\hline $\begin{array}{l}\text { Uric acid } \\
\text { stone }\end{array}$ & $\begin{array}{l}\text { Allopurinol, Potassium } \\
\text { citrate }\end{array}$ \\
\hline $\begin{array}{l}\text { Cystine } \\
\text { stone }\end{array}$ & $\begin{array}{l}\text { Potassium citrate, Thiopronin, } \\
\text { Captopril }\end{array}$ \\
\hline $\begin{array}{l}\text { Infection } \\
\text { stone }\end{array}$ & $\begin{array}{l}\text { Ammonium chloride, } \\
\text { Antibiotics }\end{array}$ \\
\hline
\end{tabular}

stone formers. They should drink 2.5-3 litres of water a day. The second level includes specific dietary recommendations based on comprehensive analytical tests to identify any underlying metabolic derangement and composition of removed stones. The third level is pharmacological agents.

Pharmacological agents like thiazides, allopurinol and potassium citrate have been shown to reduce the occurrence of stones in certain subgroups of patients (Panel 2). Adverse effects and poor compliance are

\section{Panel 1 Preventive measures for stone recurrence}

\begin{tabular}{|c|l|l|}
\hline Level 1 & General advice & $\begin{array}{l}\text { A diet consisting of fruits, vegetables, low salt, low protein } \\
\text { and a balanced intake of calcium, fats and carbohydrate. } \\
\text { Drink 2.5-3 litres of water a day. Annual US Scan KUB }\end{array}$ \\
\hline Level 2 & Specific dietary advice & $\begin{array}{l}\text { Once the individual metabolic derangement is identified, wider } \\
\text { restriction of food stuffs according to the disorder }\end{array}$ \\
\hline Level 3 & Pharmacological agents & $\begin{array}{l}\text { Thiazide, Potassium citrate, Allopurinol, Orthophosphate } \\
\text { Thiopronin, Captopril, Antibiotics }\end{array}$ \\
\hline
\end{tabular}


obstacles for these drugs as these should be taken over very long periods to prevent a single stone event. In addition sophisticated laboratory facilities with dedicated staff are required for detection and diagnosis of underlying metabolic derangements in order to identify the subgroups. Hence second and third level preventive measures are generally reserved for aggressive stone formers who develop recurrent stones that grow fast despite above mentioned changes in habits and life style.

Too many dietary and life style restrictions during the entire life purely to prevent stones may not be practical and realistic in most stone formers. One may rather identify small stones early and treat with minimally invasive procedures like shock wave lithotripsy. Hence an annual ultrasonography of the urinary tract is a sensible way of following up all stone formers. It would also be an opportunity to remind them regarding the necessity to drink adequate amounts of liquids and to have a balanced diet while maintaining a healthy BMI.

\section{References}

1. Abeygunasekera AM. Urinary stone disease in Sri Lanka. The Ceylon Medical Journal 2004: 49; 41-43

2. Turney BW. Trends in urological stone disease British Journal of Urology International 2011; 24 : 382-386

3. Sas D. Increasing incidence of kidney stones in children evaluated in the emergency department. Journal of Paediatrics 2010: 157; 132-137

4. Preminger GM, Assimos DG, Lingeman JE, et al. Chapter 1: AUA guideline on management of staghorn calculi: diagnosis and treatment recommendations Journal of Urology 2005; 173: 191-200

5. Knoll T. Epidemiology, Pathogenesis and Pathophysiology of Urolithiasis. European Urology 2010; Supplement 9: 802-806

6. Knoll T, Leusmann DB, Fahlenkamp D, WendtNordahl G, Schubert G. Urolithiasis through the ages - data from more than 200,000 stone analysis. Journal of Urology 2011; 185: 13041311

7. Abeygunasekera Anuruddha M. Urinary Stone Disease in Sri Lanka, Author Publication. 2006

8. Abeygunasekera A, Nirupika H, Bulegoda H. An observational study of staghorn calculi in Sri Lanka. Ceylon Medical Journal 2002; 47: 115116

9. Chandrajith R, Wijewardana G, Dissanayake CB, Abeygunasekera A. Biomineralogy of human urinary calculi (kidney stones) from some geographic regions of Sri Lanka. Environment Geochemistry and Health 2006; 28: 393-399

10. Tiselius H-G. Epidemiology and medical management of stone disease British Journal of Urology International 2003: 91; 758-767

11. Gnessin E, Lingemann JE, Evan AP. Pathogenesis of renal calculi. Turkish Journal of Urology 2010; 36: 190-199

12. Moe OW. Kidney stones: pathophysiology and medical management. Lancet 2006; 367: 333-344

13. Grases F, Costa-Bauza A, Prieto RM, Conte A, Servera A. Renal papillary calcification and the development of calcium oxalate monohydrate papillary renal calculi: a case series study. BMC Urology 2013; 13: 14-19

14. Kim Sc, Coe FL, Tinmouth WW, et al. Stone formation is proportional to papillary surface coverage by Randall's plaque Journal of Urology 2005; 173: 117-119

15. Evan AP, Lingeman JE, Coe FL, et al. Randall's plaque of patients with nophrolithiasis begins in basement membrane of thin loop of Henle. Journal of Clinical Investigations 2003; 111: 607-616

16. Matlaga BR, Williams JC,Kim SC, et al. Endoscopic evidence of calculus attachment to Randall's plaque. Journal of Urology 2006; 175: 1720-1724

17. Stoller ML, Meng MV, Abrahams HM, Kane JP. The primary stone event: a new hypothesis involving a vascular etiology. Journal of Urology 2004; 171: 1920-1924

18. Chen HS. Increased risk of urinary tract calculi among patients with diabetes mellitus. A population based cohort study. Urology 2011; 42: 432-435

19. Jeong IG. Association between metabolic syndrome and the presence of kidney stones in a screened population. American Journal of Kidney Diseases 2011; 58: 393-98

20. Tiselius H-G. Recurrence prevention in patients with urinary tract stone disease. The Scientific World Journal 2004: 4:35-41

21. Borghi L, Meschi T, Amato F, et al. Urinary volume, water and recurrences in idiopathic calcium nephrolithiasis: a 5-year randomised prospective study. Journal of Urology 1996; 155: 839-843

22. Popovtzer MM, Stein P, Rubinger D, Friedlaender MM. Kideny stones and drinking water New England Journal of Medicine 1984; 310: 721-725

23. Sing PP, Barajatiya MK, Dhing S, et al. Evidence suggesting that high intake of fluoride provokes 
nephrolithiasis in tribal populations. Urological Research 2001;29: 238-244

24. Straub M, Hantmann RE. Developments in stone prevention. Current Opinion in Urology 2005; 15: 19-26

25. Curhan GC, Curhan SG. Diet and urinary stone disease. Current Opinion in Urology 1997; 7: 222225

26. Wallace RB. Urinary tract stone occurrence in the Women's health initiative (WHI) randomized clinical trial of calcium and vitamin D supplements. American Journal of Clinical Nutrition 2011; 94: 270-277

27. Rosa M, Usa P, Miano R, Kim FJ, et al. Recent findings and new technologies in nephrolithiasis: a review of the recent literature. BMC Urology 2013; 13: 10-20

28. Singh I. Prospective randomised clinical trial comparing phytotherapy with potassium citrate in management of minimal burden $(<8 \mathrm{~mm})$ nephrolithiasis. Urology Annals 2011;2; 75-81

29. Arasaratnam V, Balakumar S, Senthuran A, Rajendraprasad R. A study of Tribulus terrestris extract on risk factors for urinary stone in normal subjects and urolithic patients. Journal of National Science Foundation of Sri Lanka 2010; 38: 187191 